\title{
No evidence to support use of glass ionomer as a fissure sealant in primary molars
}

\author{
In pre-school children at high risk of developing dental caries can glass \\ ionomer fissure sealant placed on primary molars decrease the incidence \\ of dental caries?
}

\begin{abstract}
Chadwick BL, Treasure ET, Playle RA. A randomised controlled trial to determine the effectiveness of glass ionomer sealants in pre-school children. Caries Res 2005; 39:34-40
\end{abstract}

Design Randomised controlled trial in primary care setting. Intervention 508 children aged $18-30$ months from high caries areas of South Wales with caries-free first primary molars were recruited to the trial after informed consent. All children $(n=508)$ received a standard package of dental health education. Children in the test group $(n=241)$ had their first primary molars sealed with glass ionomer. All the children were re-examined once at varying intervals between 12 and 30 months. Outcome measure Decayed, missing and filled teeth ( $\mathrm{dmft})$ and presence of glass ionomer sealant.

Results Analysis of the caries data revealed no significant difference between test and control groups for any of the parameters examined. Examination of the confidence intervals showed no indication that there might be a difference even if the sample size had been increased.

Conclusions There is no evidence that the intervention as used in this population had any effect on caries incidence and it cannot be recommended as a clinical procedure.

\section{Commentary}

This paper addresses the problem of preventing dental caries in pre-school children with the use of glass ionomer (GI) as dental sealant. The potential of GI to form a chemical bond to enamel, so there is no need to etch prior to use, and as a fluoride releasing material with possible cariostatic effect is a benefit worth investigating.

There is agreement that the retention rate of GI sealants is poorer than resin based materials, but it is argued that even when glass-ionomer sealants have been partly or completely lost, there is usually a benefit to the patient because the fluoride released from the material will have made the enamel harder.

Traditional reviews ${ }^{1}$ suggest the use of GI as sealant when it is not possible to use a resin sealant, for example due to poor patient compliance. This recommendation is adopted by most of clinical guidelines for caries prevention in pre-school children. $^{2-4}$

On the other hand, recent systematic reviews ${ }^{5,6}$ have found insufficient evidence to support the use of GI sealants. The present study helps to fill the gap in the evidence in this respect. It addressess a clearly focused issue with a clinical placebo controlled trial. The methods of randomization are not clearly stated in the paper and this is the only weakness in the report. The main clinical outcome is the reduction of caries in the teeth with GI sealant with a secondary aim of identifying any difference in caries prevalence for the whole mouth. The drop-out rate $(11.6 \%$ at 3

Address for correspondence: BL Chadwick, Department of Dental Health and Biological Sciences, Dental School, University of Wales College of Medicine, Cardiff, CF14 4XY, UK. E-mail: Chadwickb1@cardiff.ac.uk years follow-up) was acceptable and well compensated for at the recruitment step. The problems that faced the researchers with recruitment and the acceptability of the dental intervention in parents are reported in another paper. ${ }^{7}$ Both test and control groups received a standard package of dental health education with the test group also receiving GI sealant applications in their first primary molars.

The main results indicate a low retention rate (18.7\% of teeth), which is even lower than previous reports. The researchers applied the GI sealant in conditions of relative isolation and no suction, which could explain this. In the caries increment, there was no significant difference between the groups $(2.8 \%$ [95\% CI 2.6-8.3\%]). That represents, in clinical terms, a number needed to treat (NNT) of 35 [95\% CI 12-40]. The authors mention three possible explanations for this: 1) a low level of caries baseline, 2) that the burden of disease in this population is so severe that the intervention was not of sufficient strength to have any effect and 3) that the intervention as used in this research had no effect.

The present report concludes that there is no evidence that a single application of GI sealant in pre-school children reduces caries. More research is needed to help to clarify whether this intervention would be effective if applied in an area with higher caries levels, such as in developing countries. At present the available evidence does not support recommendations to use of GI sealant in primary molars.

\section{Practice point}

- The available evidence does not support the use of GI as a sealant in primary molars.

\section{Sergio Uribe}

Department of Preventive and Paediatric Dentistry, Graduate School, Faculty of Dentistry, University of Valparaiso, Chile

1. Simonsen RJ. Glass ionomer as fissure sealant - a critical review. J Public Health Dent 1996; 56:146-149.

2. Preventing dental caries in children at high caries risk: targeted prevention of dental caries in the permanent teeth of 6-16 year olds presenting for dental care. A national clinical guideline. Scottish Intercollegiate Guidelines Network (SIGN); 2000. 39 p. Publication no. 47.

3. Welbury R, Raadal M, Lygidakis N. Guidelines on the use of Pit and Fissures Sealants in Paediatric Dentistry: an EAPD policy document. Available at http:// www.eapd.gr/Guidelines/Guidelines PitFissures.htm.Accessed April 25, 2005.

4. American Academy of Pediatric Dentistry. Clinical guidelines. Pediatr Dent 2003; 25(Suppl):50-110.

5. Ahovuo-Saloranta A, Hiiri A, Nordblad A, Worthington H, Makela M. Pit and fissure sealants for preventing dental decay in the permanent teeth of children and adolescents. Cochrane Database Syst Rev 2004; 3:CD001830.

6. Mejare I, Lingstrom P, Petersson LG, et al. Caries-preventive effect of fissure sealants: a systematic review. Acta Odontol Scand 2003; 61:321-330.

7. Chadwick BL, Treasure ET. Primary care research: difficulties recruiting preschool children to clinical trials. Int J Paediatric Dent 2005; 15:197-204.

Evidence-Based Dentistry (2005) 6, 35.

doi:10.1038/sj.ebd.6400334 